\title{
Clinical validation of nursing diagnosis Fragile Elderly Syndrome
}

\author{
Validação clínica do diagnóstico de enfermagem Síndrome do Idoso Frágil \\ Validación Clínica del diagnóstico de enfermería del Síndrome Anciano Frágil
}

\section{Fabiana Maria Rodrigues Lopes de Oliveira' ORCID: 0000-0002-5966-232X \\ Natalia Pessoa da Rocha Leal' ORCID: 0000-0001-6404-5580}

Fabíola de Araújo Leite Medeiros" ORCID: 0000-0002-0834-1155

Jacira dos Santos Oliveira"t' ORCID: 0000-0002-3863-3917

Maria Miriam Lima da Nóbrega"II ORCID: 0000-0002-6431-0708

Oriana Deyze Correia Paiva Leadebal"' ORCID: 0000-0002-3342-8746

Maria das Graças Melo Fernandes"' ORCID: 0000-0002-1694-1206

Centro universitário de João Pessoa. João Pessoa, Paraíba, Brazil.

"Universidade Estadual da Paraíba. Campina Grande,

Paraíba, Brazil.

"'Universidade Federal da Paraíba. João Pessoa, Paraíba, Brazil.

How to cite this article: Oliveira FMRL, Leal NPR, Medeiros FAL, Oliveira JS, Nóbrega MML, Leadebal ODCP, et al. Clinical validation of the nursing diagnosis of frail elderly syndrome. Rev Bras Enferm. 2021;74(Suppl 2): e20200628. https://doi.org/10.1590/0034-7167-2020-0628

\section{Corresponding author:}

Fabiana Maria Rodrigues Lopes de Oliveira fabianarodriguesenf@yahoo.com.br

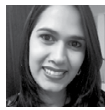

EDITOR IN CHIEF: Antonio José de Almeida Filho ASSOCIATE EDITOR: Rafael Silva

\section{ABSTRACT}

Objective: to clinically validate the nursing diagnosis of NANDA-I Frail Elderly Syndrome in hospitalized elderly. Method: a methodological study, guided by the STROBE instrument, composed of 40 elderly people admitted to a teaching hospital in Paraíba, Brazil. The last phase of Hoskins' Nursing Diagnostic Validation Model: clinical validation was adopted. Data collection took place from August to December 2018. The data were analyzed using univariate descriptive statistics. It was approved by the hospital's ethics and research committee. Results: nine defining characteristics were validated; seven risk factors; six populations at risk and two associated conditions. Conclusion: the validation of the nursing diagnosis of the Frail Elderly Syndrome in our socio-cultural context was considered appropriate, being an important step for critical thinking that underlies the decision-making of nurses in the care of the frail elderly, as well as professional practice.

Descriptors: Nursing; Validation Studies; Nursing Diagnosis; Frail Elderly; Syndrome.

\section{RESUMO}

Objetivo: validar clinicamente o diagnóstico de enfermagem da NANDA-I Síndrome do Idoso Frágil em idosos hospitalizados. Método: estudo metodológico, direcionado pelo instrumento STROBE, com a participação de 40 idosos internados em um hospital-escola na Paraíba, Brasil. Adotou-se a última fase do Modelo de Validação de Diagnóstico de Enfermagem de Hoskins: validação clínica. Os dados foram coletados de agosto a dezembro de 2018 e analisados por estatística descritiva de natureza univariada, sendo aprovado pelo comitê de ética em pesquisa do referido hospital. Resultados: foram validados nove características definidoras; sete fatores de risco; seis populações em risco e duas condições associadas. Conclusão: a validação do diagnóstico de enfermagem Síndrome do Idoso Frágil em nosso contexto sociocultural foi considerada apropriada. Trata-se de uma etapa importante tanto para o desenvolvimento de um pensamento crítico que fundamenta a tomada de decisão dos enfermeiros no cuidado ao idoso frágil como para a prática profissional.

Descritores: Enfermagem; Estudo de Validação; Diagnóstico de Enfermagem; Idoso Fragilizado; Síndrome.

\section{RESUMEN}

Objetivo: validar clínicamente el diagnóstico de enfermería del NANDA-I, Síndrome del Adulto Mayor Frágil en ancianos hospitalizados. Método: estudio metodológico, direccionado por el instrumento STROBE, compuesto por 40 ancianos internados en un hospital escuela de Paraíba, Brasil. Se adoptó la última fase del Modelo de Validación del Diagnóstico de Enfermería de Hoskins: validación clínica. La recolección de datos se llevó a cabo entre agosto y diciembre de 2018. Los datos se analizaron mediante estadística descriptiva de naturaleza univariada, aprobado por el comité de ética del referido hospital. Resultados: se validaron nueve características definitorias; siete factores de riesgo; seis poblaciones de riesgo y dos condiciones asociadas. Conclusión: la validación del diagnóstico de enfermería del Síndrome del Adulto Mayor Frágil en nuestro contexto sociocultural ha sido considerada como apropiada, tratándose de una etapa importante para el desarrollo de un pensamiento crítico que fundamenta la toma de decisiones de los enfermeros en el cuidado del adulto mayor frágil, así como también, la práctica profesional.

Descriptores: Enfermería; Estudio de Validación; Diagnóstico de Enfermería; Adulto Mayor Fragilizado; Síndrome. 


\section{INTRODUCTION}

The worldwide age pyramid has undergone major changes due to the drop in fertility and mortality rates, causing a substantial increase in the elderly population ${ }^{(1)}$. In Brazil, these changes have been taking place more rapidly, with an estimate that in 2025 there will be nearly 32 million elderly people, ranking sixth world population with people aged over 60 years ${ }^{(2)}$. Aging is characterized as a heterogeneous, complex, gradual, and dynamic phenomenon, in which functional, anatomical, psychological, and social changes occur, involving individual and social aspects, which result in an increased vulnerability to intrinsic and extrinsic factors and the chance of morbidity and mortality, disabilities, and dependence ${ }^{(3)}$.

From there, the concept of frailty evolves in the field of geriatrics, which concerns the not ideal clinical situation, of a multi-causal and dynamic nature, interconnected to the elderly's life path. The term frail elderly, emerged in 1970 to describe individuals who were in disadvantaged socioeconomic conditions, with physical weakness and cognitive impairment ${ }^{(4)}$, however, since then, there is still no consensus on the theoretical and operational definition of the elderly frail syndrome. Nursing is an old profession that throughout its historical construction has sought to establish its professional practice on scientific principles. Amid the knowledge produced so far, the Nursing Process stands out, aiming at diagnosing and treating human responses to potential and real health problems, through a unique work or way of doing professional (Nursing Care Systematization) that is based on a system of ethical and moral values, and on the technical-scientific knowledge of the professional practice ${ }^{(5)}$.

A considerable part of this process of delimiting Nursing work is the standardization of its language through taxonomies. Considering this, several terminologies for nursing diagnoses, interventions, and results have been established, which aim, among other aspects, to provide a view of the knowledge of the area of expertise; to organize the phenomena; and showing the logical connection between the factors that can be managed by the professionals. Although these terminologies were formulated among the most widespread in the world, the taxonomy of nursing diagnoses of NANDA-I stands out ${ }^{(6)}$.

Frailty was included in the classification of diagnoses by NANDA International (NANDA-I) in the 2015 - 2017 version, with the title "Frail Elderly Syndrome", defined as: "dynamic state of unstable balance that affects the elderly who undergoes deterioration in one or more health dimension (physical, functional, psychological or social) and leads to increased susceptibility to adverse health effects, specifically, disability". It belongs to the "health promotion" dimension, the "health control" class and because it is a syndrome, its defining characteristics are established by other diagnoses of the same taxonomy. Regarding related factors, they permeate physical, social, functional, and psychological aspects ${ }^{(6)}$.

A study that carried out the concept analysis of the nursing diagnosis Frail Elderly Syndrome, found sixteen attributes related to it, among these, thirteen were NANDA-I diagnoses and the others were defining characteristics of other nursing diagnoses. Moreover, three defining characteristics pointed out in this review are in the structure of the diagnosis of Nursing Syndrome of the Fragile Elderly, as related factors ${ }^{(7)}$.
Regarding the antecedents of the concept, the study above mentioned found ten related factors associated with the concept, among which, only three, correspond to diagnosis-related factors. Two of these are not part of the Frail Elderly Syndrome diagnosis framework, while the others are found as constituents of the population at risk or associated conditions. Furthermore, it is emphasized that the referred investigation did not involve the categories of the population at risk and associated conditions, since at the time of its development the taxonomy did not present these topics in its structure $^{(7)}$. Another investigation that also carried out the analysis of that concept, found twenty antecedents, seventeen attributes, and eight consequences for the same concept ${ }^{(8)}$.

It is worth saying that some nursing diagnoses, like the one found in the study mentioned above, do not have a well-developed theoretical-conceptual basis. In this way, in practical reality, nurses are faced with sets of indicators that are present in various diagnoses, which creates uncertainty in the judgment and a greater chance of formulating inaccurate diagnoses. Furthermore, some elements do not match the observed reality. To increase diagnostic reliability, it is necessary to subject them to a validation process, improving the diagnostic determinants and making their use safe.

Given the relevance of the "Frail Elderly Syndrome" diagnosis for the effectiveness of nursing care directed to the frail elderly, there is a lack of studies that support the identification or use of this diagnosis, in the professional experience of Nursing, especially in the Brazilian scenario. Besides that, there is no consensus in the literature on the theoretical definition of frailty, given the multifactorial and multidimensional character of the syndrome, it becomes complex to define operational attributes that are reliable to the aspects experienced by frail elderly people. In this context, it is worth mentioning that the defining characteristics and related factors in the NANDA-I taxonomy may not be compatible with the real needs of the elderly in frailty condition, which makes resolutive nursing care impossible.

\section{OBJECTIVE}

Clinically validate the nursing diagnosis of NANDA-I Frail Elderly Syndrome in hospitalized elderly.

\section{METHODS}

\section{Ethical aspects}

For the whole research process, the ethical aspects that regulate research with human beings in Resolution 466/2012 of CNS/MS/ BRASIL were observed. For this, the Informed Consent Form (ICF) was provided, in which participants were guaranteed information about the study, anonymity, confidentiality related to the data provided, and the choice to give up participating in any stage of the investigation. For the elderly person who was physically or cognitively unable to grant acceptance, the informed consent form was signed by their companion.

\section{Design, study setting, and period}

This is a methodological study, in which the STROBE instrument ${ }^{(9)}$ was used as a methodological guide. For clinical validation 
of the nursing diagnosis Frail Elderly Syndrome of this study, the last phase of Hoskins' Nursing Diagnostic Validation Model ${ }^{(10)}$, Clinical Validation, was adopted, in which the characteristics of the phenomena listed in the nursing diagnosis are identified in clinical practice. This work was carried out in a teaching hospital located in the state of Paraíba, Brazil, from August to December 2018, in the morning and afternoon shifts, through the first stage of the Nursing Process. This stage was carried out, simultaneously, by two diagnosticians, nurses, and doctoral students in nursing, with experience in assistance, research and teaching focused on the elderly's health.

\section{Population and sample; inclusion and exclusion criteria}

The study population comprised the elderly who were admitted to the two clinical units of the above-mentioned hospital at the time of data collection. About the sample size, Hoskins ${ }^{(10)}$ does not establish the necessary number of participants. It is worth mentioning that in the five months of data collection, all the elderly who were attended in the mentioned units were recruited to participate in the study, according to the following inclusion criteria: being 60 years old or more, both genders, and that after the assessment by an instrument that classifies fragility, the Edmonton Frail Scale, translated and validated for the Brazilian reality ${ }^{(11)}$, were classified as frail. Elderly people who were not in physical and cognitive conditions accept to participate and who was alone in the room at the time of collection were excluded. Thus, the final sample consisted of 40 elderly people. It should also be noted that because it is a hospital that typically attends chronic pathologies, associated with the fact that the elderly patient already has long periods of hospitalization as a characteristic, the turnover in beds is low, which was contributing factor to the impossibility of extending data collection.

\section{Study protocol}

Data collection took place through interviews, using a semistructured data collection instrument that had two sections, the first with sociodemographic and clinical data of the investigated elderly. The second part encompassed the defining characteristics, related factors, populations at risk, and associated conditions of the nursing diagnosis of NANDA-I (2018) Frail Elderly Syndrome. Considering that each defining characteristic of the referred diagnosis corresponds to another nursing diagnosis, in this second section of the instrument, their respective diagnostic indicators were also incorporated.

\section{Analysis of results and statistics}

The data were entered and organized in an electronic database, using the Statistical Package for Social Science (SPSS), version 20.0. Processing included encoding, typing, and editing the data. Data analysis was carried out quantitatively using descriptive statistics of a univariate nature for all variables, obtaining frequency distributions for the categorical variables analyzed and descriptive measures for the numerical variables. Central tendency measurements (mean, median, minimum, maximum) and scale (standard deviation) were calculated, with 95\% confidence intervals for the mean value of these variables.

For statistical analysis, Hoskins ${ }^{(10)}$ suggests the calculation of the frequency of occurrence of the attributes, as well as the weighted reliability relationships between evaluators, proposed by Fehring ${ }^{(12-13)}$. Considering this, agreement tests were used on the presence or absence of diagnostic indicators, calculated using the Kappa test, with a $95 \%$ confidence interval. Values of $\mathrm{k}$ close to one suggest a high degree of agreement between the evaluators. Thus, we included in the study the determinant with a coefficient greater than 0.50 , while those that reached a score lower than 0.50 were excluded, following the precepts pointed out by Fehring (1987) ${ }^{(12-13)}$. Finally, the total diagnosis score was calculated using the weighted average of all diagnostic indicators included in the validation. It is worth mentioning that the diagnosis is considered satisfactory when the total score is above $0.60^{(12-13)}$.

\section{RESULTS}

Regarding the sociodemographic characterization, of the 40 patients analyzed, $70 \%$ were female, $27.5 \%$, had an average age of 73.3 ( \pm 7.97 ) years, with a minimum and maximum age range of, 60 and 87 years, respectively. Regarding marital status, married people (45\%) prevailed, followed by widowers (35\%). Regarding color/race, $50 \%$ of the patients declared themselves mixed race and $42.5 \%$ white. Of the $72.5 \%$ who attended school, $61.54 \%$ had up to six years of schooling. As for the family arrangement, $92.5 \%$ lived with family members, with their own average income of $R \$ 1,384.80$ ( \pm $1,330.28)$, and the average family income was $R \$ 2,087.87$ ( $\pm 1,448.91)$.

Concerning the health conditions of the elderly analyzed, the percentage of conscious and oriented respondents was $80 \%$, in which $75.76 \%$ reported being fulfilled with life, $47.5 \%$ of the elderly had four comorbidities and $65 \%$ used more than five medications a day.

Regarding the data related to the nursing diagnosis of NANDA-I Frail Elderly Syndrome, of the 13 defining characteristics contemplated in the diagnosis under study, nine presented an identification frequency higher than $50 \%$, a high level of agreement between the two diagnoses, and the reliability coefficient consistent with the indication that they remain in the diagnosis structure were "Impaired walking"; "Decreased cardiac output"; "Bathing self-care deficit"; "Toileting self-care deficit"; "Dressing self-care deficit"; "Fatigue"; "Activity intolerance"; "Impaired physical mobility" and "Imbalanced Nutrition: Less than Body Requirements" (Table 1).

For the related factors of the Frail Elderly Syndrome, of the 19 factors that make up the diagnosis, seven had a reliability coefficient greater than 0.50: "Impaired balance"; "Decrease in muscle strength"; "Muscle weakness"; "Activity intolerance"; "Average daily physical activity is less than recommended for age and gender"; "Fear of falling" and "Impaired physical mobility" (Table 2).

As for the population at risk, the items with the highest values for frequency, the agreement between diagnosticians and reliability were:"Low educational level"; "Economically disadvantaged”; "History of falls"; "Prolonged hospitalization"; "Age over seventy" and "Female gender", which should be included in the composition of the nursing diagnosis "Frail Elderly Syndrome" (Table 3). 
Table 1 - Defining characteristics of the nursing diagnosis "Frail Elderly Syndrome", according to frequency, the index of agreement between the diagnosticians, and the reliability coefficient, João Pessoa, Paraíba, Brazil, 2019 ( $\mathrm{N}=40)$

\begin{tabular}{|c|c|c|c|c|c|c|}
\hline Defining characteristics & n (D1*) & $\%$ (D1*) & $n(D 2 * *)$ & $\%(D 2 * *)$ & Kappa & IC*** \\
\hline Impaired walking & 38 & 95 & 38 & 95 & 1.00 & 0.95 \\
\hline Impaired physical mobility & 34 & 85 & 32 & 80 & 0.83 & 0.80 \\
\hline Fatigue & 32 & 80 & 31 & 77.5 & 0.75 & 0.80 \\
\hline Activity intolerance & 33 & 82.5 & 30 & 75 & 0.78 & 0.74 \\
\hline Dressing self-care deficit & 26 & 65 & 25 & 62.5 & 0.84 & 0.62 \\
\hline Bathing self-care deficit & 24 & 60 & 24 & 60 & 1.00 & 0.60 \\
\hline Imbalanced nutrition: less than body requirements & 26 & 65 & 24 & 60 & 0.89 & 0.60 \\
\hline Toileting self-care deficit & 23 & 57.5 & 23 & 57.5 & 1.00 & 0.57 \\
\hline Decreased cardiac output & 22 & 55 & 21 & 52.5 & 0.95 & 0.52 \\
\hline Deficit in self-care: eating & 18 & 45 & 18 & 45 & 1.00 & 0.45 \\
\hline Social isolation & 18 & 45 & 16 & 40 & 0.89 & 0.45 \\
\hline Hopelessness & 15 & 37.5 & 15 & 37.5 & 1.00 & 0.42 \\
\hline Impaired memory & 11 & 27.5 & 12 & 30 & 0.94 & 0.28 \\
\hline
\end{tabular}

Table 2 - Related factors of the nursing diagnosis "Syndrome of the Elderly Fragile", according to frequency, the index of agreement between the diagnosticians and the reliability coefficient, João Pessoa, Paraíba, Brazil, 2019 ( $N=40$ )

\begin{tabular}{|c|c|c|c|c|c|c|}
\hline Related factors & n (D1*) & $\%(D 1 *)$ & n (D2**) & $\%(D 2 * *)$ & Kappa & $I C^{* * *}$ \\
\hline Fear of falling & 32 & 80 & 34 & 85 & 0.83 & 0.80 \\
\hline Average daily physical activity is less than recommended for gender and age & 36 & 90 & 31 & 77.5 & 0.20 & 0.77 \\
\hline Impaired physical mobility & 30 & 75 & 33 & 82.5 & 0.63 & 0.74 \\
\hline Muscle weakness & 32 & 80 & 29 & 72.5 & 0.52 & 0.72 \\
\hline Decrease in muscle strength & 32 & 80 & 26 & 65 & 0.63 & 0.65 \\
\hline Activity intolerance & 25 & 62.5 & 26 & 65 & 0.30 & 0.62 \\
\hline Impaired balance & 21 & 52.5 & 22 & 55 & 0.55 & 0.51 \\
\hline Sedentary lifestyle & 31 & 77.5 & 18 & 45 & 0.38 & 0.48 \\
\hline Sadness & 18 & 45 & 19 & 47.5 & 0.85 & 0.45 \\
\hline Anxiety & 20 & 50 & 17 & 42.5 & 0.75 & 0.42 \\
\hline Decrease in energy & 17 & 42.5 & 15 & 37.5 & 0.48 & 0.37 \\
\hline Obesity & 3 & 7.5 & 2 & 5 & 0.79 & 0.28 \\
\hline Immobility & 8 & 20 & 10 & 25 & 0.86 & 0.20 \\
\hline Depression & 7 & 17.5 & 7 & 17.5 & 0.83 & 0.17 \\
\hline Social isolation & 9 & 22.5 & 2 & 5 & -0.09 & 0.12 \\
\hline Exhaustion & 12 & 30 & 2 & 5 & 0.22 & 0.10 \\
\hline Malnutrition & 3 & 7.5 & 4 & 10 & 0.84 & 0.07 \\
\hline Insufficient social support & 2 & 5 & 1 & 2.5 & 0.66 & 0.01 \\
\hline Insufficient knowledge of modifiable risk factors & 1 & 2.5 & 0 & 0 & 0.00 & 0.00 \\
\hline
\end{tabular}

Note: ${ }^{*}$ D1 = Diagnostician 1;D2 = Diagnostician 2; /C = Reliability Index.

Table 3 - The population at risk of the nursing diagnosis "Frail Elderly Syndrome", according to frequency, the index of agreement between the diagnosticians and the reliability coefficient, João Pessoa, Paraíba, Brazil, 2019 ( $N=40)$

\begin{tabular}{|c|c|c|c|c|c|c|}
\hline Population at risk & n (D1*) & $\%(D 1 *)$ & n (D2**) & $\%(D 2 * *)$ & Kappa & IC $* * *$ \\
\hline Female gender & 28 & 70 & 28 & 70 & 1.00 & 0.70 \\
\hline Age $>70$ years & 26 & 65 & 26 & 65 & 0.95 & 0.65 \\
\hline Low educational level & 24 & 60 & 26 & 65 & 0.89 & 0.60 \\
\hline Prolonged hospitalization & 24 & 60 & 25 & 62.5 & 0.84 & 0.60 \\
\hline Economically disadvantaged & 20 & 50 & 21 & 52.5 & 0.45 & 0.50 \\
\hline History of falls & 20 & 50 & 22 & 55 & 0.90 & 0.50 \\
\hline Living alone & 3 & 7.5 & 3 & 7.5 & 1.00 & 0.07 \\
\hline Social vulnerability & 2 & 5 & 6 & 15 & 0.19 & 0.06 \\
\hline Ethnicity other than Caucasian & 7 & 17.5 & 1 & 2.5 & 0.22 & 0.05 \\
\hline
\end{tabular}

Note: *D1 = Diagnostician 1;D2 = Diagnostician 2; $/ C=$ Reliability Index.

Table 4 - Associated conditions of the nursing diagnosis "Frail Elderly Syndrome", according to frequency, the agreement index between the diagnosticians and the reliability coefficient, João Pessoa, Paraíba, Brazil, 2019 ( $(N=40)$

\begin{tabular}{|c|c|c|c|c|c|c|}
\hline Associated conditions & n (D1*) & $\%(D 1 *)$ & n $(\mathrm{D} 2 * *)$ & $\%(D 2 * *)$ & Kappa & $I C^{* * *}$ \\
\hline Chronic disease & 40 & 100 & 39 & 97.5 & 0.00 & 0.96 \\
\hline Walking 4 meters requires $>5$ seconds & 32 & 80 & 36 & 90 & 0.62 & 0.80 \\
\hline Unintentional loss of $>4,5 \mathrm{~kg}$ of body weight in one year & 22 & 55 & 19 & 47.5 & 0.85 & 0.47 \\
\hline Endocrine regulatory dysfunction & 14 & 35 & 13 & 32.5 & 0.94 & 0.32 \\
\hline Alteration in cognitive functioning & 8 & 20 & 6 & 15 & 0.83 & 0.15 \\
\hline Unintentional loss of $20 \%$ of body weight over one year & 15 & 37.5 & 5 & 12.5 & 0.39 & 0.15 \\
\hline Sensory deficit & 7 & 17.5 & 5 & 12.5 & 0.61 & 0.12 \\
\hline Sarcopenic obesity & 5 & 12.5 & 2 & 5 & 0.54 & 0.06 \\
\hline Sarcopenia & 2 & 5 & 2 & 5 & 1.00 & 0.05 \\
\hline Altered coagulation & 1 & 2.5 & 1 & 2.5 & 1.00 & 0.02 \\
\hline Decrease in serum 25-hydroxyvitamin D concentration & 1 & 2.5 & 1 & 2.5 & 1.00 & 0.02 \\
\hline Suppressed inflammatory response & 2 & 5 & 0 & 0 & 0.00 & 0.01 \\
\hline
\end{tabular}

Note: * D1 = Diagnostician 1;D2 = Diagnostician 2; IC = Reliability Index. 
According to information presented in table 4, of the 12 associated conditions included in the diagnosis, "Walking less than four meters requires more than five seconds" and "Chronic disease" were identified more frequently by the diagnosticians, and an adequate reliability coefficient for inclusion in the diagnosis.

Regarding the diagnosis "Frail Elderly Syndrome", the frequency was $95 \%(n=38)$ and $92.5 \%(n=37)$, according to the judgment of diagnosticians 1 and 2, respectively. The agreement for the general diagnosis was 0.78 (kappa) and the reliability coefficient was 0.96 . Considering that the total score was 0.69 , the validation of the studied diagnosis is considered satisfactory, according to Fehring ${ }^{(12)}$.

\section{DISCUSSION}

The nursing diagnosis of NANDA-I Taxonomy Frail Elderly Syndrome has 13 defining characteristics, 19 related factors, 10 identifiers for populations at risk, and 14 associated conditions. In our study, 9 defining characteristics, 7 related factors, 6 populations at risk, and 2 associated conditions were validated. Thus, it should be observed that NANDA-I encourages the conduct of clinical validation studies, aimed at ensuring that the diagnostic indicators in the taxonomy reflect the reality found.

Thus, the findings of this study show that Impaired walking, Decreased cardiac output Bathing self-care deficit, Toileting selfcare deficit, Dressing self-care deficit, fatigue, activity intolerance, impaired physical mobility, and Imbalanced nutrition: less than body requirements are defining characteristics relevant to the identification of the nursing diagnosis Frail Elderly Syndrome. While Impaired balance, Decrease in muscle strength, Muscle weakness, Activity intolerance, Average daily physical activity is less than recommended for age and gender, Fear of falling, and Impaired physical mobility are important related factors of the diagnosis.

Moreover, Low educational level, Economically disadvantaged, Prolonged hospitalization, History of falls, Age under seventy, Female gender revealed to be the population at risk. While walk of less than 4 meters that requires more than five seconds and Chronic disease emerged as associated conditions of the diagnosis.

Altered mobility is part of a wide range of information about the physiological deterioration of aging and about diseases that affect breathing, metabolism, and motor function. In this sense, impaired physical mobility is a common manifestation of frailty in the elderly and a sensitive indicator of acute illness. It is one of the main components of the genesis of frailty and indicates a greater likelihood of adverse events, such as falls ${ }^{(14)}$.

Impaired physical mobility in fragile people can be understood as a sign of the system's general loss. This is the reason for addressing the outcomes of altered mobility as some of the so-called "geriatric giants" (postural instability, immobility). For this same reason, measuring mobility impairment can help determine the prognosis ${ }^{(15)}$. An 11.8 years follow-up study carried out with elderly people over 65 , demonstrated that low mobility is a strong predictor of mortality in both genders, considering a variety of related lifestyle and health factors ${ }^{(16)}$.

Generally, activity limitation is assessed in terms of the need for assistance in basic, instrumental, and advanced activities of daily living (ADLs, IADL, and BADL, respectively). The indicators of the scales that measure the performance of the elderly person in the performance of the ADL assess the most complex acts of daily life, which are impaired early in the incapacity, while the indicators related to the IADL and BADL measure the most basic actions such as bathing, dressing, going to the bathroom, body transfer, food and walk ${ }^{(17)}$.

This is because the attributes of the frail syndrome, such as the variables contained in its phenotype, are also part of the genesis of functional disability ${ }^{(18)}$. In this scenario, the disability observed in frail elderly people is expressed, among other factors, by bathing self-care deficit, toileting, and dressing. Corroborating, a prospective study conducted with 2,420 elderly people, observed that those classified as fragile had a greater decline in basic activities of daily living ${ }^{(18)}$.

There is also a growing consensus that fragility indicators include declines associated with a decrease in muscle strength, endurance, balance, impaired walking, activity intolerance, and fatigue. Also, frail individuals had a higher prevalence of cardiovascular comorbidities, such as coronary artery disease, heart failure, stroke, hypertension, and acute myocardial infarction. Such health changes are related to decreased cardiac output, common in frailty ${ }^{(19)}$.

Considering this, although walking dysfunctions are common in aging, due to musculoskeletal, neurological, and vascular disorders, their analysis has been widely used to predict frailty ${ }^{(20)}$. A study carried out in Massachusetts - USA found that impaired walking was the most common characteristic presented by frail elderly ${ }^{(21)}$.

Research carried out with 5,532 elderly people living in several states in Brazil, proved that the level of physical activity, muscle weakness, and slow steps are the items that most impact the determination of frailty, and that the reduced step length (indicating a decrease in muscle strength of lower limbs) is sensitive to classify the level of frailty ${ }^{(20)}$.

About activity intolerance, this represents a key indicator of frailty, in such a way that the increase in the levels of physical conditioning can prevent or even reverse the development of the syndrome. Nevertheless, the pattern of physical activity in frailty is marked by a decrease in the distances covered (due to fatigue and decreased strength), a decrease in the complexity of movement, and a deficit in the physiological adaptation response (heart rate, hormonal rhythms, postural balance) ${ }^{(20)}$.

As for fatigue, it is defined in the NANDA-I taxonomy ${ }^{(6)}$, as an "oppressive and prolonged feeling of exhaustion and decreased ability to perform physical and mental work at the usual level". This feeling of exhaustion or decline in physical function may be the first sign of a bad prognosis, instead of being a sign of depression or functional disability ${ }^{(22)}$. A study carried out with 385 Brazilian elderlies, found that exhaustion was the third most prevalent frailty criterion in the investigated population, being related to females ${ }^{(23)}$.

The complaint of fatigue is even greater when observing comorbidities. Prospective research that followed frail elderly people found that the increase in the number of morbidities after one year of hospital discharge was 1.26 times more likely to worsen self-reported fatigue ${ }^{(24)}$. This relationship is linked to the decrease in the energy supply inherent in frailty, which worsens in the presence of multiple morbidities, causing greater spending of energy to fulfill daily activities, with increased fatigue $e^{(24)}$.

It should also be observed that unintentional weight loss indicates Imbalanced nutrition: less than body requirements, 
experienced by frail elderly people, which is part of the downward spiral of frailty ${ }^{(25)}$. It is also worth mentioning that the decrease in the prevalence of this variable may be linked to the different ways of assessing the phenomenon by the researchers, making it difficult to standardize and compare the research carried out, as it is information, often self-reported, is subject to forgetfulness by the interviewees.

The task of preparing one's own food can be correlated with imbalanced nutrition, especially when the person already has mobility limitations. When other variables influence this process, such as the elderly being inserted in a hospital environment, or the spouse's death, who was responsible for this chore, this condition can become even worse. The role of low protein and possibly vitamin E intake, along with a persistent inflammatory state seems to be part of this path ${ }^{(25-26)}$.

The low level of physical activity is indicated in the literature as one of the most prevalent phenotype components in frail syndrome, which can be expressed in clinical validation by the average daily physical activity is less than recommended for age and gender $^{(23-24)}$. Research carried out with Brazilian elderly people points out that frail elderly people report a worsening in the level of physical activity when compared to the previous year ${ }^{(20)}$.

Besides the decrease in the level of physical activity, frail elderly people have a cut in the length and variability of daily walking episodes, as there is a more static and less complex physical activity behavior in fragile individuals. In this context, the "complexity loss paradigm" related to frailty is reflected not only by physiological systems but also by the behavior of daily physical activity. The low level of physical activity is also able to predict hospitalizations and death ${ }^{(20)}$.

Corroborating a study carried out with hospitalized elderly, found that the most prevalent phenotype component was the decrease in handgrip strength, emphasizing the importance of the decrease in muscle strength in the genesis of the syndrome ${ }^{(27)}$. This is also the constituent of the phenotype that first manifests itself, arising since the installation of pre-frailty, which can serve as an indication of increased vulnerability in the initial stages of frailty $^{(23-24)}$. It is worth mentioning that the decrease in muscle strength is a direct indication of sarcopenia, which, together with neuroendocrine and immunological changes, forms the tripod of the frail syndrome.

In this context, the decrease in muscle strength, and the level of physical activity, often observed in frail elderly people, causes them to further restrict their activities for fear of falling ${ }^{(27)}$. The fear of falling encourages the adoption of protection strategies (short steps, decreased balance, use of upper limbs as support) when performing BADL and IADL, as well as a reduction in the frequency with which they are performed, to avoid the event of falls. However, all this surveillance feeds the decline in mobility and, consequently, in muscle mass, resulting in an increase in the number of falls and worsening of frailty ${ }^{(28)}$.

NANDA-I describes the category Population at risk as being "a group of people who share common factors that make their members susceptible to a specific human response"(6). Considering the aspects in the literature and the clinical validation of the phenomenon, now presented, the frail syndrome is related to low educational level, especially when it is less than five years of study ${ }^{(28)}$.
Low educational level reflects the deprivation of other basic rights throughout life. It is noteworthy that being economically disadvantaged and having a low educational level, are clear aspects of a social exclusion that leads to greater vulnerability to developing various health problems. The person who does not have good financial conditions is the same person who had to stop studying to help to support the family and, consequently, had less access to health services, either due to lack of knowledge, or because they did not have the financial support to take greater care of their health. There is, therefore, a mutual influence between low educational level and low income in frail elderly people, who, given this, will show greater deficit in self-care, decreased quality of life, and restricted access to health services, especially those of promotion and prevention ${ }^{(29)}$.

Frailty is more frequent in women ${ }^{(25)}$. A study carried out with Brazilians in outpatient care found a 1.85 times higher odds ratio for women to be frail when compared to the male gender. Women naturally have a much lower percentage of lean mass and muscle strength when compared to the opposite sex, especially after the decline in hormone production after menopause, which can cause a high predisposition to sarcopenia ${ }^{(30)}$.

Moreover, the gerontological literature shows that high life expectancy, observed in females, takes place with the increase in chronic health conditions and disabilities ${ }^{(20)}$. Another aspect highlighted is the social divergences between the genders, in which the woman's figure, sometimes, still plays the role of a housewife, with a small social coexistence, and little economic independence, which may also predispose to the increased female fragility ${ }^{(31)}$.

The age over seventy is a condition highly associated with frailty $^{(29)}$. A study carried out with 1,327 Spanish elderly people showed an average increase of $14 \%$ in the chances of frailty in the population for each additional year after 65 years of age, resulting in a prevalence of $19 \%$ in those aged 75 or over and $40.2 \%$ after 85 years $^{(31)}$, verifying that for each additional year, the chance of becoming fragile increases by $10 \%{ }^{(31)}$.

Such finding is linked to the anatomical and physiological changes inherent to the aging process, which cause a decline in all body systems, with emphasis on the endocrine, immune, muscular and nervous systems, also pathological conditions, and risks to functionality and health ${ }^{(32)}$. Besides reflecting the varying of homeostatic and hemodynamic regulation, which decreases the body's resistance and resilience, in adverse contexts, which will predispose to frailty ${ }^{(23)}$. It is worth saying that although there is an evident relationship between aging and frailty, not every elderly person becomes fragile, implying common, but not identical, mechanisms.

As for the history of falls, the literature shows that frail elderly people tend to suffer a greater number of falls when compared to pre-frail and non-frail individuals ${ }^{(25)}$. The explanation for this association is not precisely clarified, however, the aging process causes a decrease in visual acuity, body balance, mobility, and all physical aspects, variables that are directly related to the increase in the case of falls. All this decline associated with the frail syndrome will increase the number of falls, since these two outcomes have factors in common, such as sarcopenia ${ }^{(20)}$. However, it is worth noting that these variables are associated, so frailty can influence 
the increase in the number of falls, and the occurrence of falls can contribute to the development of frailty ${ }^{(30)}$.

Frailty is also correlated with a higher number of hospitalizations $^{(23)}$. Faced with all their physiological, emotional, and social decline, fragile individuals show a decrease in resilience and the ability to react to stressful situations, which predisposes them to more injuries and, consequently, a greater number of consultations and hospitalizations. Furthermore, the hospital environment can also cause functional decline, making recovery difficult and increasing its degree of fragility ${ }^{(31)}$.

The category Conditions associated with nursing diagnosis, as proposed by NANDA-I, is composed of "medical diagnoses, injuries, procedures, medical devices or pharmaceutical agents", and these conditions cannot be modified by the nurse ${ }^{(6)}$. As explained, one of the associated conditions found after the clinical validation of the nursing diagnosis Frail Elderly Syndrome was the walk of less than 4 meters that requires more than five seconds.

A study carried out with elderly Brazilians, proved that the decrease in muscle strength in the lower limbs was related to the decrease in walking speed and frailty, so that the rate of chances for elderly people to be fragile was 4.8 times higher among those who had this deficit ${ }^{(30)}$, and may be up to ten times more likely to become fragile ${ }^{(25)}$. A survey of 1,327 elderly people in Spain, 10.5\% of whom were fragile, states that fragility could be excluded in $99.9 \%$ of individuals in the sample aged 75 or over with walking speed $\geq 0.8 \mathrm{~m} / \mathrm{s}$ in $100 \%$ of those with walking speed $\geq 0.9 \mathrm{~m} / \mathrm{s}^{(31)}$.

Fragility is also associated with the onset and/or increase of chronic diseases, through mechanisms that affect the basic physiological functioning fundamental to organic stability, such as inflammation and imbalances in the regulatory mechanisms of the central nervous system; or through the decline in activity levels ${ }^{(31)}$.

Among the most frequent health problems associated with frailty, cardiovascular disease; systemic arterial hypertension; subclinical peripheral vascular disease; brain stroke; leakage; dementia; depression ${ }^{(25)}$; diabetes mellitus; chronic kidney disease; peripheral arterial disease; Congestive heart failure; myocardial infarction; cerebrovascular disease; osteoporosis; neoplasm; fecal and urinary incontinence stand out ${ }^{(31)}$.

Besides the above, several studies indicate an increase in comorbidities in fragile individuals, as they are more vulnerable to stressors, less able to respond to adverse events, and decreased physiological reserves, which can result in the onset of diseases, due to failures in the mechanisms that keep homeostasis ${ }^{(29)}$. This correlation reflects a bidirectional relationship so that the onset of diseases can predispose to frailty, as well as physical weakness, which can lead to chronic conditions. However, not every elderly person with morbidities is fragile and vice versa, making two terms appear in the literature: primary frailty, when there is no disease; and secondary frailty when there are morbidities ${ }^{(23)}$.

Supporting this analysis, a study carried out with 2,324 elderly people in Malaysia, found that the fragile group had a greater number of chronic diseases and that every 10 years the frailty prevalence increased at least three times ${ }^{(33)}$. Specifically considering arterial hypertension as morbidity involved, in some way, in the genesis of frailty, it is emphasized that this constitutes one of the most frequent health changes in elderly people, because, with the aging process, changes in the structure and functioning of the cardiovascular system, such as the decrease in the elasticity of the vessel walls, which culminates in increased peripheral vascular resistance and, consequently, changes in systolic blood pressure and diastolic blood pressure ${ }^{(31)}$.

A study carried out with 900 elderly Brazilians, identified lower levels of diastolic and average blood pressure in frail elderly when compared to non-frail ones. In the multivariate analysis, only the mean pressure remained associated with frailty, so that with each $1 \mathrm{mmHg}$ reduction in pressure values, the probability of being fragile increased by $1.4 \%$. It is possible that a drop in blood pressure starts as a consequence of primary heart disease and decreased cardiac output that results in systemic hypoperfusion, contributing to sarcopenia in these individuals, which can contribute to the process of atrophy and loss of muscle resistance ${ }^{(32)}$.

Fragile individuals are more likely to have diagnosed dementia, being six times more likely to have vascular dementia and four times more likely to develop Alzheimer's disease. Cardiovascular risk factors, which are known to predispose people to frailty, are believed to cause vascular changes in the brain, which can lead to vascular dementia. Furthermore, frailty and Alzheimer's have common pathogenesis and risk factors, such as lifestyle, physical inactivity, and smoking ${ }^{(20)}$.

Regarding depression, studies have shown its association with frail syndrome ${ }^{(25)}$. Research carried out with 301 Irish elderly people, showed 2.6 times more chance of frail or pre-frail elderly people to present depression when compared to the healthy ones. However, the study did not define the type of causal relationship between depression and frailty ${ }^{(25)}$. If on the one hand, depression, marked by changes in behavior, a decline in the level of activity and social relationship, can be a risk factor for the triggering of frailty, as well as, depressive symptoms can constitute initial manifestations of one's own syndrome ${ }^{(31)}$.

\section{Study limitations}

Study limitations concern the sample size, which may have been decisive for some indicators not reaching the cutoff point of the reliability index. Thus, it should be highlighted that this is a pioneering study on the clinical validation of the Nursing diagnosis of Frail Elderly Syndrome in the Brazilian reality, through which the complexity arising from the multifactorial genesis of the referred Syndrome was confirmed.

\section{Contributions to the field of nursing, health, or public policy}

The considerations made here may support the improvement of the creation of effective therapeutic plans with nursing interventions directed to the reality experienced by the frail elderly, ensuring the improvement of nursing care and the quality of life of the referred population, since the theoretical basis, provided in this study, raises critical thinking and diagnostic reasoning for nurses who experience care for the elderly.

\section{CONCLUSION}

The study achieved the proposed objective of clinically validating the nursing diagnosis of NANDA-I (2018) Fragile Elderly Syndrome in 
hospitalized elderly. Of the 13 defining characteristics contemplated, nine had a high-reliability coefficient: impaired walking; decreased cardiac output; bathing self-care deficit; toileting self-care deficit; Dressing self-care deficit; fatigue; activity intolerance; impaired physical mobility and Imbalanced nutrition: less than body requirements.

About related factors, seven had a reliability coefficient greater than 0.50: impaired balance; decrease in muscle strength; muscle weakness; activity intolerance; average daily physical activity is less than recommended for age and gender; fear of falling and impaired mobility. It is worth noting that the results of this study suggest that the terms activity intolerance and impaired physical mobility remain only in the category of defining characteristics, to increase diagnostic accuracy.

As for the population at risk, the items with the highest frequency values were low educational level; economically disadvantaged; history of falls; prolonged hospitalization; age over seventy, and female. Also, of the 12 associated conditions included in the diagnosis, walking less than four meters requires more than five seconds and chronic disease reached an adequate reliability coefficient for inclusion in the diagnosis.

\section{REFERENCES}

1. Maia PHS, Ferreira EF, Melo EM, Vargas AMD. Occurrence of violence in the elderly and its associated factors. Rev Bras Enferm. 2019;72(Suppl 2):64-70. https://doi.org/10.1590/0034-7167-2018-0014

2. Instituto Brasileiro de Geografia e Estatística (IBGE). Projeção da população do Brasil e das Unidades da Federação [Internet]. 2020 [cited 2020 May 25]. Available from: https://www.ibge.gov.br/apps/populacao/projecao/

3. Lana LD, Schneider RH. Síndrome de fragilidade no idoso: uma revisão narrativa. Rev Bras Geriatr Gerontol. 2014;17(Suppl 3):673-80. https:// doi.org/10.1590/1809-9823.2014.12162

4. Warmoth K, Lang I, Phoenix C, Abraham C, Andrew M, Hubbard R, et al. "Thinking you're old and frail': a qualitative study of frailty in older adults. Ageing Soc. 2016;36(Suppl-7):1483-500. https://doi.org/10.1017/S0144686X1500046X

5. Benedet SA, Gelbcke FL, Amant LN, Souza Padilha MI, Pires DP. Nursing process: systematization of the nursing care instrument in the perception of nurses. Rev Pesqui: Cuid Fundam. 2016;8(Suppl-3):4780-8. https://doi.org/10.5902/2236583419805

6. NANDA International. NANDA-I. Diagnósticos de enfermagem da NANDA-I: definições e classificação 2018-2020. 11. ed. Porto Alegre: Artmed; 2018.

7. Linck CL. Diagnóstico de enfermagem "síndrome da fragilidade no idoso": análise de conceito[Tese]. 2015. Programa de Pós-graduação em Enfermagem, Universidade Federal do Rio Grande do Sul, Rio Grande do Sul.

8. Oliveira FMRL, Barbosa KTF, Rodrigues MMP, Fernandes MGM. Síndrome do idoso frágil: análise conceitual de acordo com Walker e Avant. Rev Bras Enferm. 2020;73(Suppl 3):e20190601. https://doi.org/10.1590/0034-7167-2019-0601

9. Cuschieri S. The STROBE guidelines. Saudi J Anaesth. 2019;13(Suppl 1):S31. https://doi.org/10.4103/sja.SJA_543_18

10. Hoskins LM. Clinical validation, methodologies for nursing diagnoses research. In: Caarol JRM (Ed.). Classification of nursing diagnoses: proceedings of the eighth conference of North American Nursing Diagnosis Association. Philadelphia: Lippincott, 1989. 126-31 p.

11. Fabricio-Wehbe SCC. Adaptação cultural e validação da “Edmonton Frail Scale” [Tese]. Escola de Enfermagem de Ribeirão Preto, USP. São Paulo, 2008. $131 \mathrm{p}$.

12. Fehring RJ. Methods to validate nursing diagnoses. Heart Lung; 1987. 625-629 p.

13. Fehring RJ. Symposium of Validation Models: the Fehring Model. In: Johnson, R.M.C. Classification of nursing diagnoses: proceedings of the tenth conference of North American Nursing Diagnosis Association. Philadelphia: Lippincott; 1994. 55-62 p.

14. Bellal J, Faisal SJ. The mobility and impact of frailty in the Intensive Care Unit. Surg Clin N Am. 2017;97:1199-213. https://doi.org/10.1016/j. suc.2017.07.007

15. Hatheway OL, Mitnitski A, Rockwood K. Frailty affects the initial treatment response and time to recovery of mobility in acutely ill older adults admitted to hospital. Age Ageing. 2017;46:920-25. https://doi.org/10.1093/ageing/afw257

16. Bergland A, Jørgensen L, Emaus N. Mobility as a predictor of all-cause mortality in older men and women: 11.8 year follow-up in the Troms $\varnothing$ study. BMC Health Serv Res. 2017;17(1):22. https://doi.org/10.1186/s12913-016-1950-0

17. Ding YY, Kuha J, Murphy M. Pathways from physical frailty to activity limitation in older people: Identifying moderators and mediators in the English Longitudinal Study of Ageing. Exp Gerontol. 2017;98:169-76. https://doi.org/10.1016/j.exger.2017.08.029

18. Op Het Veld LPM, Ament BHL, van Rossum E. Can resources moderate the impact of levels of frailty on adverse outcomes among (pre-) frail older people? a longitudinal study. BMC Geriatr. 2017;17(Suppl-1):185. https://doi.org/10.1186/s12877-017-0583-4

19. Kramer DB, Tsai T, Natarajan P, Tewksbury E, Mitchell SL, Travison TG. Frailty, physical activity, and mobility in patients with cardiac implantable electrical devices. J Am Heart Assoc. 2017;6(Suppl-2):e004659. https://doi.org/10.1161/JAHA.116.004659

20. Silva SLAD, Neri AL, Ferrioli E, Lourenço RA, Dias RC. Fenótipo de fragilidade: influência de cada item na determinação da fragilidade em idosos comunitários-Rede Fibra. Ciênc Saúde Coletiva. 2016;21(11):3483-3492. https://doi.org/10.1590/1413-812320152111.23292015

21. Anzaldi LJ, Davison A, Boyd CM, Leff B, Kharrazi H. Comparing clinician descriptions of frailty and geriatric syndromes using electronic health records: a retrospective cohort study. BMC Geriatr. 2017;17(Suppl 1):248. https://doi.org/10.1186/s12877-017-0645-7 
22. Pao YC, Chen CY, Chang Cl, Chen CY, Tsai JS. Self-reported exhaustion, physical activity, and grip strength predict frailty transitions in older outpatients with chronic diseases. Medicine (Baltimore). 2018;97(Suppl 23):e10933. https://doi.org/10.1097/MD.0000000000010933

23. Calado LB, Ferriolli E, Moriguti JC, Martinez EZ, Lima NKC. Frailty syndrome in an independent urban population in Brazil (FIBRA study): a cross-sectional populational study. São Paulo Med J. 2016;134(Suppl 5):385-92. https://doi.org/10.1590/1516-3180.2016.0078180516

24. Marchiori GF, Tavares DMS. Mudanças nas condições de fragilidade e componentes do fenótipo em idosos após hospitalização. Rev LatinoAm Enfermagem. 2017;25:e2905. https://doi.org/10.1590/1518-8345.1417.2905

25. Sandoval-Insausti H, Pérez-Tasigchana RF, López-García E, García-Esquinas E, Rodríguez-Artalejo F, Guallar-Castillón P. Macronutrients intake and incident frailty in older adults: a prospective cohort study. J Gerontol A Biol Sci Med Sci. 2016;71(Suppl 10):1329-34. https://doi. org/10.1093/gerona/glw033

26. Souza GA, Giacomin KC, Firmo JOA. O cuidado com as pessoas idosas frágeis na comunidade: uma revisão integrativa. Rev Bras Geriatr Gerontol. 2020;23(6). https://doi.org/10.1590/1981-22562020023.190134

27. Ma L, Tang Z, Zhang L, Sun F, Li Y, Chan P. Prevalence of frailty and associated factors in the community-dwelling population of China. J Am Geriatr Soc. 2018;66(Suppl 3):559-64. https://doi.org/ 10.1111/jgs.15214

28. Nascimento PPP, Batistoni SST, Neri AL. Frailty and depressive symptoms in older adults: data from the FIBRA study - UNICAMP. Psicol: Reflex Crít. 2016;29:16. https://doi.org/10.1186/s41155-016-0033-9

29. Nozoe M, Kubo H, Kanai M, Yamamoto M, Shimada S, Mase K. Sarcopenia risk and diabetes mellitus are independent factors for lower limb muscle strength in elderly patients with acute stroke: a cross-sectional study. Nutrition. 2020. https://doi.org/ 10.1016/j.nut.2020.111025

30. Castell MV, Sánchez M, Julián R, Queipo R, Martín S, Otero Á. Frailty prevalence and slow walking speed in persons age 65 and older: implications for primary care. BMC Fam Pract. 2013;14:86. https://doi.org/10.1186/1471-2296-14-86

31. Lenardt MH, Carneiro NHK, Binotto MA, Setoguchi LS, Cechinel C. Relação entre fragilidade física e características sociodemográficas e clínicas de idosos. Esc Anna Nery. 2016;20(Suppl 4). https://doi.org/ 10.5935/1414-8145.20160097

32. Rodrigues RAP, Fhon JRS, Pontes MDLDF, Silva AO, Haas VJ, Santos JLF. Frailty syndrome among elderly and associated factors: comparison of two cities. Rev Latino-Am Enfermagem. 2018;26. https://doi.org/ 10.1590/1518-8345.2897.3100 